\title{
New insight into the oncogenic mechanism of the retroviral oncoprotein Tax
}

\author{
Hua Cheng ${ }^{1,2}$, Tong Ren ${ }^{1,2}$, Shao-cong Sun ${ }^{3}$ \\ ${ }^{1}$ Penn State Hershey Cancer Institute, Hershey, PA 17033, USA \\ ${ }^{2}$ Microbiology and Immunology, Penn State University College of Medicine, Hershey, PA 17033, USA \\ ${ }^{3}$ Department of Immunology, The University of Texas M.D. Anderson Cancer Center, Houston, TX 77030, USA \\ $\triangle$ Correspondence: hcheng@hmc.psu.edu \\ Received May 15, 2012 Accepted June 7, 2012
}

\begin{abstract}
Human T cell leukemia virus type 1 (HTLV-1), an etiological factor that causes adult $T$ cell leukemia and lymphoma (ATL), infects over 20 million people worldwide. About 1 million of HTLV-1-infected patients develop ATL, a highly aggressive non-Hodgkin's lymphoma without an effective therapy. The $\mathrm{pX}$ region of the HTLV-1 viral genome encodes an oncogenic protein, Tax, which plays a central role in transforming CD4+ T lymphocytes by deregulating oncogenic signaling pathways and promoting cell cycle progression. Expression of Tax following viral entry is critical for promoting survival and proliferation of human $T$ cells and is required for initiation of oncogenesis. Tax exhibits diverse functions in host cells, and this oncoprotein primarily targets IKB kinase complex in the cytoplasm, resulting in persistent activation of NF-KB and upregulation of its responsive gene expressions that are crucial for $\mathrm{T}$ cell survival and cell cycle progression. We here review recent advances for the pathological roles of Tax in modulating IKB kinase activity. We also discuss our recent observation that Tax connects the IKB kinase complex to autophagy pathways. Understanding Tax-mediated pathogenesis will provide insights into development of new therapeutics in controlling HTLV-1associated diseases.
\end{abstract}

KEYWORDS human $T$ cell leukemia virus type 1 , IKB kinase complex, NF-kB, lipid raft microdomains, autophagy, Beclin1-PI3KC3-Bif1 complex

\section{TAX INDUCES PERSISTENT ACTIVATION OF NF-KB}

HTLV-1 viral genome encodes three main structural gene products including Gag, reverse transcriptase (Pol/RT) and envelope protein (Env), and it also expresses several viral regulatory proteins such as Tax, Rex and p30, p12 and p13 (Seiki et al., 1983; Hattori et al., 1984; Hidaka et al., 1988; Koralnik et al., 1993). These viral gene transcripts are directed from a promoter at the 5 '-end of long terminal repeat (LTR). In addition, the viral 3'-LTR transcribes an antisense gene product called HTLV-I basic leucine zipper factor (HBZ) (Gaudray et al., 2002). Early studies showed that the molecular clone of HTLV-1 with disrupted tax gene failed to transform primary $T$ cells (Ratner et al., 2000), implicating a critical role of Tax in mediating $T$ cell oncogenesis. Further analysis suggests that the oncogenic action of Tax involves activation of NF-KB (Yamaoka et al., 1996), a transcriptional factor that plays key roles in the pathogenesis of a variety of human diseases including chronic inflammation and cancer (Karin and Greten, 2005). An HTLV-1 infectious clone expressing a mutant Tax protein defective in NF-KB activation had no capacity to transform T cells. Consistently, one of the characteristic features of ATL is the constitutive activity of $\mathrm{NF}-\mathrm{KB}$, which is thought to be a prerequisite for induction of ATL (Mori et al., 1999).

\section{TAX AND HBZ WORK COOPERATIVELY IN BALANCING NF-KB ACTIVITY DURING THE PROCESS OF T CELL TRANSFORMATION}

Among all viral proteins expressed from HTLV-1, Tax and HBZ have been shown to deregulate NF-KB signaling with opposing activities. Tax activates both canonical and non-canonical NF-KB pathways, whereas HBZ inhibits the activity of the NF-KB subunit, RelA/p65 (Harhaj and Harhaj, 2005; Zhao et al., 2009). Emerging evidence demonstrates that both Tax and HBZ play important roles in T cell trans- 
formation with distinct roles at different stages of oncogenesis. As a viral transactivator, Tax promotes synthesis of viral transcripts through 5'-LTR, which is necessary for productive viral replication (Jeang et al., 1988; Varmus, 1988; Yip and Chen, 1990). Tax is able to promote T cell survival and proliferation and to override cell senescence, leading to immortalization and ultimately, transformation of human primary CD4 T cells (Grassmann et al., 1992; Franchini, 1995; Yoshida, 2001). Moreover, Tax transgenic mice develop leukemia (Nerenberg et al., 1987; Grossman et al., 1995). These experimental findings strongly suggest that Tax is a singly important protein from HTLV-1 to initiate oncogenesis.

Intriguingly, more than $50 \%$ of ATL cases were found to lose expression of a functional Tax protein, suggesting that Tax is no longer required at the late stage of oncogenesis. Loss of Tax expression in ATL cells is caused by several distinct mechanisms. Genetic changes in the tax gene cause disrupted Tax expression, while DNA hyper-methylation or deletion of the 5'-LTR leads to the repression of Tax transcription along with other viral transcripts (Furukawa et al., 2001; Koiwa et al., 2002; Takeda et al., 2004). Moreover, because the Tax protein is highly immunogenic, loss of Tax may be advantageous for HTLV-1-transformed T cells to escape host immunity (Jacobson et al., 1990; Kannagi et al., 1991, 1993; Satou et al., 2006). Furthermore, Tax is capable of inducing genomic instability that generates multiple somatic alterations, causing persistent oncogenic activation (Haoudi et al., 2003; Marriott and Semmes, 2005), which may contribute to the persistent activation of NF-KB in ATL cells that are deficient of Tax expression. In contrast, HBZ RNA and protein are constitutively expressed throughout all processes of HTLV-1 oncogenesis in T cells (Usui et al., 2008; Matsuoka and Green, 2009), probably because the 3'-LTR that directs HBZ expression is less susceptible to methylation or genetic disruption. The HBZ RNA promotes T cell proliferation while its protein form represses Tax-mediated transactivation of the 5'-LTR, and both HBZ RNA and protein are implicated to play important roles for maintaining malignant phenotypes of HTLV-1-transformed T cells even in the absence of Tax expression (Satou et al., 2006; Arnold et al., 2008).

Without all other viral components, Tax fails to immortalize human primary fibroblasts, and induces senescence and apoptotic death of solid tumor cells, and the Tax mutant that is defective in activating NF-KB has no ability to induce cell death (Los et al., 1998; Kamochi et al., 2002). Indeed, over-expression of Tax results in a hyperactivity of NF-KB, which in turn induces expression of some cytotoxic gene products such as TRAIL (Rivera-Walsh et al., 2001). Consistent with this phenomenon, Tax, when expressed alone, rarely immortalizes human primary $\mathrm{T}$ cells (Bellon et al., 2010). Hence, it is conceivable that balancing the activities of Tax and HBZ, particularly in the regulation of NF-KB activity, is crucial in HTLV-1 induced oncogenesis. It can be rea- sonably assumed that co-expression of Tax and HBZ could facilitate the process of $T$ cell immortalization or even transformation. This notion, however, is yet to be validated. Conclusively, HTLV-1-associated T cell transformation is mediated through Tax-dependent, persistent activation of NF-KB particularly at the early stage of oncogenesis.

\section{TAX TARGETS IKB KINASE COMPLEX TO ACTIVATE NF-KB SIGNALING}

The transcriptional factor NF-kB is essential for T lymphocyte activation and therefore, has a prominent role in host immunity. Deregulated NF-KB signaling is seen in the pathological conditions such as autoimmune disease, chronic inflammation and oncogenesis (Bacher and Schmitz, 2004; Karin and Greten, 2005; Prasad et al., 2010; Ben-Neriah and Karin, 2011). In resting T cells, NF-KB is sequestered in the cytoplasm in complex with its inhibitor, IKB. Engagement of $\mathrm{T}$ cell receptor (TCR) on $T$ cells leads to sequential activation of upstream signaling molecules, transmitting activation signal to the IKB kinase (IKK) complex. This multimeric protein complex comprises two catalytic subunits, IKKa and IKK $\beta$, and one regulatory subunit, IKKY, together with the Hsp90 chaperone complex (Ghosh et al., 1998; Harhaj and Sun, 1998; Rothwarf et al., 1998; Li et al., 1999; Pomerantz et al., 2002; Wang et al., 2002). Activated IKKa and IKK $\beta$ phosphorylate $\mathrm{IKB}$ on its $\mathrm{N}$-terminal serine residues, resulting in its ubiquitination and subsequent proteasomal degradation. Consequently, the freed NF-KB heterodimer migrates into the nucleus to activate target gene expressions. Activation of NF-KB at physiological conditions such as $\mathrm{T}$ cell activation is a transient process, whereas persistent activation of NF-KB is seen in HTLV-1-associated ATL.

Tax is distributed in the cytoplasm and the nucleus, shuttling between these two subcellular compartments in HTLV-1-transformed T cells. Evidence showed that activation of IKB kinases occurs in the cytoplasm, and a portion of the Tax protein is constitutively associated with the Golgi apparatus where Tax directs relocation of the IKK complex to this structure for activation (Harhaj et al., 2007; Huang et al., 2009). In which Golgi sub-structure that the Tax protein resides is presently not clear. Given the evidence that Tax facilitates assembly of viral particles in microtubule-organizing center (MTOC) where Tax interacts with the myristoylated capsid protein Gag, it is tempting to reason that Tax is associated with the outer membrane of the Golgi apparatus. In non-lymphoid cells, the subcellular localization of the Tax protein is diverse depending on specific cell types. In human embryonic kidney cells (HEK293), Tax is accumulated in the perinuclear "hot spot" in the cytoplasm reminiscent of the Golgi, as evidenced with co-location of Tax with caveolin-1, a Golgi marker protein (Fig. 1A). Tax is predominantly distributed in the nucleus with a perinuclear Golgi distribution pattern in HT1080 fibrosarcoma cells (Fig. 1C, left image), and 
A

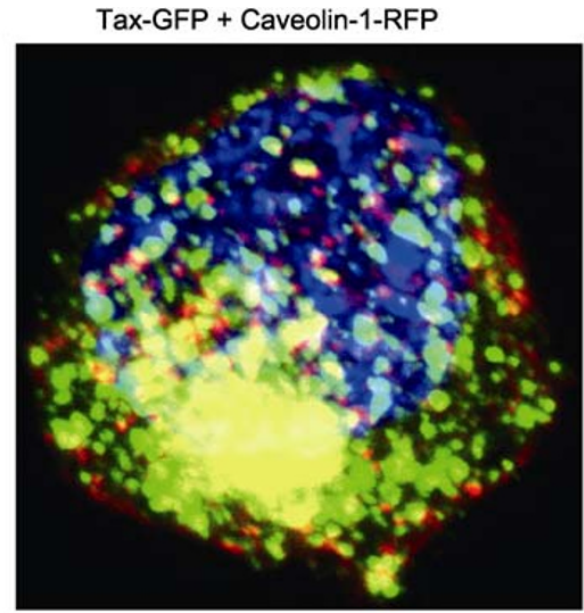

B

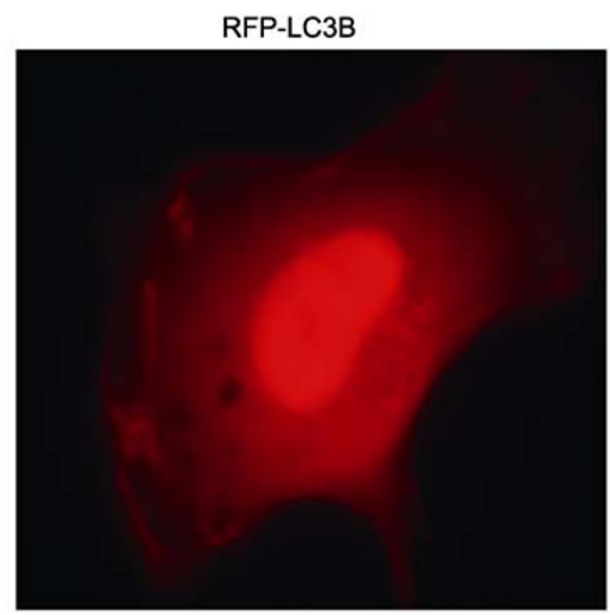

C

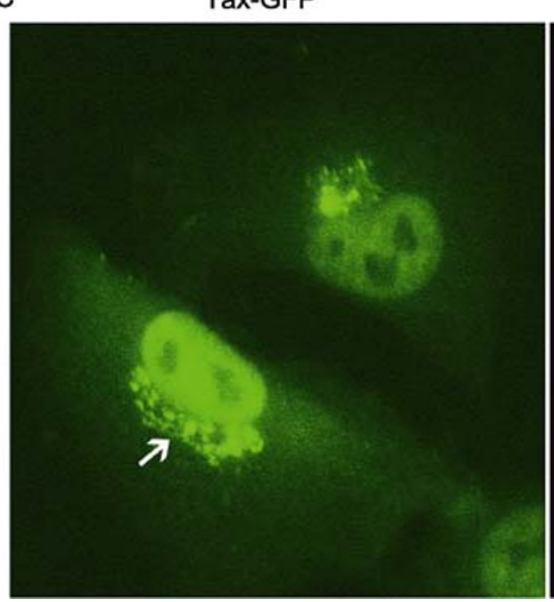

RFP-LC3B

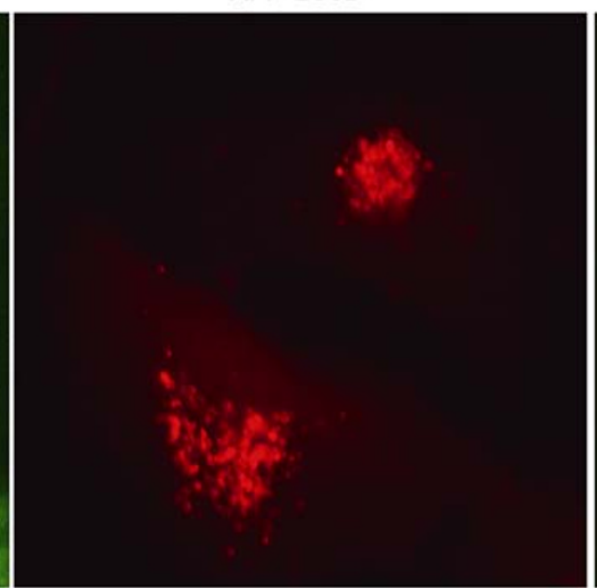

Merge

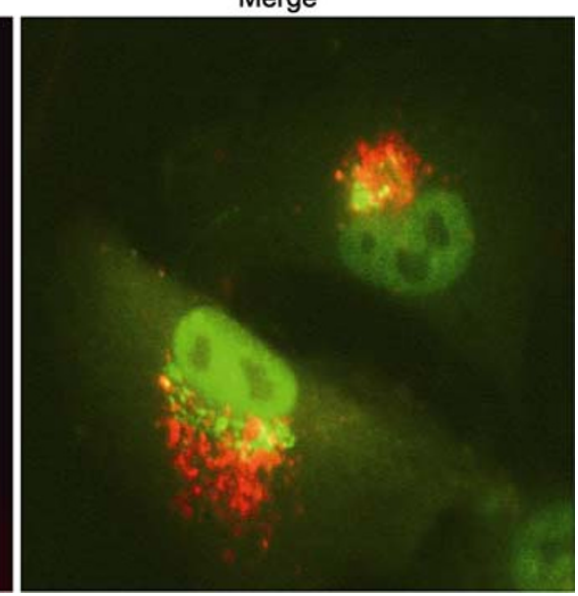

Figure 1. The subcellular distribution of Tax and its induction of autophagosome formation. (A) 3-D image of HEK293 cells co-transfected with Tax-GFP and caveolin-1-RFP, showing cytoplasmic yellow "hot spot" reminiscent of the Golgi apparatus. (B) The expression pattern of RFP-LC3B, an autophagy marker, in transiently transfected HT1080 cells, showing a nuclear accumulation and relatively even cytoplasmic distribution. (C) HT1080 cells are transiently co-transfected with Tax-GFP and RFP-LC3B. Tax-GFP is concentrated in the nucleus with a perinuclear cluster distribution, which is reminiscent of the Golgi apparatus (arrow, left image). RFP-GFP puncta are evolved from the Tax-GFP cytoplasmic clusters, representing autophagosomes and autolysosomes.

this pattern is similar to that seen in HTLV-1-transformed T lymphocytes.

Several studies suggested that Tax induces activation of NF-KB via several distinct mechanisms. Firstly, Tax is found to directly target the IKK complex, the key regulator of NF-KB signaling, in inducing the catalytic activity of IKB kinase subunits, IKKa and IKK $\beta$. The mechanistic nature of Tax modulation of the IKK activity is the physical interaction of Tax with the non-catalytic subunit, IKKY or NEMO (Chu et al., 1999; Harhaj and Sun, 1999; Jin et al., 1999; Carter et al., 2001), because Tax fails to activate IKB kinases in NEMO/IKKץdeficient cells (Xiao et al., 2001). Tax was also reported to interact with IKK $\beta$ (Sun and Ballard, 1999; Xiao and Sun, 2000), and Tax-mediated activation of NF-KB can be blocked with the dominant-negative mutant of IKK $\beta$ or small interference RNA specific for IKK $\beta$ (Carter et al., 2001; Cheng et al., 2002; Huang et al., 2009). These experimental findings indicate that IKKY is one of the key targets for Tax-mediated activation of IKK and that IKK 3 is the primary catalytic subunit stimulated by Tax in canonical NF-KB signaling. Secondly, Tax is able to activate NF-kB by modulating non-canonical pathway of NF-kB signaling. This notion is supported by the observation that Tax stimulates the activity of IKKa via interaction with $\mathrm{IKK} y$, resulting in the enhanced processing of NF-kB2/p100 in T cells (Xiao et al. 2001) Thirdly, Tax was shown to modulate the activities of mitogen-activated protein kinase/extracellular signal-regulated kinase kinase 1 (MEKK1) (Yin et al., 1998; Wu and Sun, 2007), an upstream kinase of 
IKK, and transforming growth factor beta (TGF $\beta$ ) activated kinase 1 (Tak1) by promoting the interaction of Tak1 and IKKY (Wu and Sun, 2007).

In addition, several studies showed that Tax deregulates negative regulators of NF-KB signaling. Tax induces proteasomal degradation of both $\mathrm{I} B \mathrm{~B} \alpha$ and $\mathrm{I} B \mathrm{~B} \beta$, the native inhibitors of NF-KB (McKinsey et al., 1996). We found that Tax interacts with CYLD, a deubiquitinase that negatively regulates NF-KB activity, by inactivating it (Wu et al., 2011). We previously showed that Tax targets the molecular chaperone protein Tid1 (Cheng et al., 2002). Since Tid1 maintains stability of the NF-KB-IKB complex by directly interacting with the IKK complex (Cheng et al., 2005), it is plausible that Tax deregulates Tid1 as one of the processes leading to NF-KB activation. Together, these evidences implicate that Tax-mediated activation of NF-KB is a complex process, and the precise mechanisms of Tax-mediated persistent activation of NF-KB is under active investigation.

\section{TAX RECRUITS IKB KINASES TO THE LIPID RAFT MICRODOMAINS FOR THEIR ACTIVATION}

Upon interaction of antigen-presenting cells with $\mathrm{T}$ cells through MHC-1/peptide complex and T cell receptor (TCR), tyrosine phosphorylation cascades of signaling molecules initiate. TCR proximal molecules such as ZAP70, PI3K and PKC $\theta$ are recruited into the plasma membrane lipid raft microdomains for their activation. Subsequently, the Carma1Bcl10-MALT1 complex, together with the IKK complex, is also recruited into plasma membrane lipid rafts for activation (Garofalo et al., 2002; Lee et al., 2005; Van Komen et al., 2007). Consequently, the activated IKK phosphorylates IKB, leading to its proteasomal degradation and incidentally, NF-KB activation. The activity of NF-KB is essential for T cell activation and proliferation, and the lipid raft recruitment of the IKK complex is crucial for acquiring its catalytic activity. Lipid raft microdomains are cholesterol- and sphingolipid-rich membrane regions (Simons and Ikonen, 1997; Brown and London, 1998; Simons and Toomre, 2000). Lipid rafts are synthesized from the Golgi and are recycled from the Golgi to the plasma membrane (Hansen et al., 2000; Heino et al., 2000). The microdomains are crucial membrane structures to serve as "signal transduction platforms" for mediating activation of cellular kinases in TCR signaling.

We determined whether Tax activation of NF-KB involves the lipid raft recruitment of IKK. Our data showed that IKB kinases are constitutively present in HTLV-1-transformed T cells that express Tax (Huang et al., 2009). In Tax-expressing $\mathrm{T}$ cells, intense phosphorylation of IKBa and IKKa was observed, correlating with a hyperactivity of NF-KB. Using density gradient ultracentrifugation, together with biochemical, molecular biology and imaging techniques, we found that the IKK complex and the Tax protein are constantly resided in the lipid rafts. Treatment of HTLV-1-transformed T cells with cholesterol chelate such as methyl- $\beta$-cyclodextrin $(M \beta C D)$ resulted in suppression of the NF-KB activity. This indicates that the lipid raft-associated IKKs are catalytically active. We further demonstrated that Tax is a viral lipid raft modulator that can recruit the IKK complex to the Golgi-lipid rafts through physical interaction with IKKY (Huang et al., 2009). Other lipid raft-attached viral proteins can also modulate $\mathrm{NF}-\mathrm{kB}$ activity. For example, the latent infection membrane protein 1 of the Epstein-Barr virus resides in the plasma membrane-associated lipid rafts and mediates engagement with tumor necrosis factor receptor-associated TRAF to activate NF-kB via the NF-kB inducing kinase (NIK)/IKKa-dependent pathway (Luftig et al., 2004). The Nef protein from human immunodeficiency virus type 1 is a myristoylated protein that associates with the plasma membrane lipid raft and potentiates NF-KB activity (Herbein et al., 2008). Unlike these viral proteins, Tax appears to be attached to the intracellular lipid rafts in the Golgi (Fig. 1A), by bypassing upstream signaling molecules of TCR. This action is highly efficient, directly targeting the IKK complex. The mechanism for how the lipid raft-recruited kinases gain a catalytic activity is presently not clear. A method was developed with attaching an $\mathrm{N}$-terminal myristoylation signal to a given kinase such as PI3K or Akt. The lipid raft targeting of $\mathrm{PI} 3 \mathrm{~K}$ or Akt results in its spontaneous and persistent activation in the absence of extracellular stimuli (Arcaro et al., 2007). Similarly, an activated kinase library was generated with attachment of a myristoylation signal to a panel of cellular kinases, and $\mathrm{IKK} \varepsilon$ was identified to be one of the cellular oncoproteins for malignant transformation of breast epithelial cells (Boehm et al., 2007). By extension, the persistent presence of IKK in lipid rafts indicates that the IKKs are constitutively activated in HTLV-1-transformed T cells. Interestingly, Tax does not contain a consensus lipid raft signal peptide and therefore, Tax may interact with a cellular lipid raft-associated protein for targeting to this subcellular structure. This hypothesis remains to be investigated. Our recent data showed that the C-terminal domain is critical for the lipid raft targeting of Tax and for Tax activation of NF-KB (Ren et al., unpublished data).

\section{TAX CONNECTS IKB KINASE COMPLEX TO AUTOPHAGY PATHWAYS}

It is known that TCR engagement results in activation of IKK and PI3KC1, and induces autophagy that is important for $\mathrm{T}$ cell proliferation (Gerland et al., 2004; Li et al., 2006). Likewise, Tax activates both IKK and PI3KC1 (Huang et al., 2009; Saito et al., 2010). Although these two kinases have been reported to exhibit opposing activities in regulating autophagy (Wu et al., 2009; Criollo et al., 2010), the overall balance is in favor of autophagy in HTLV-1-infected T cells, which exhibit constitutively high level of autophagy (Ren et al., unpublished data). These experimental results strongly suggest that au- 
autophagy is beneficial for oncogenesis.

In response to metabolic stress, autophagosomes form and sequester aggregated cellular proteins and organelles, which subsequently fuse with lysosomes for degradation (Wang and Klionsky, 2003; Cuervo, 2004; Klionsky, 2005; Mizushima and Komatsu, 2011). This process generates energy for the need of metabolically stressed cells. Autophagy is evolutionally conserved among living organisms, and its primary function is pro-survival. Evidence about the crucial role of deregulated autophagy in tumor initiation and progression is beginning to evolve. Tumor initiation is characterized by the acquisition of defects in apoptosis, allowing malignant cells to overcome oncogene activation-induced senescence or apoptosis. Tumor growth typically exceeds the rate of angiogenesis during the early stages of malignancy, causing the center of the tumor to experience constant hypoxic and metabolic stresses. These stresses trigger autophagy-mediated survival machinery in cancer cells (Mathew et al., 2007; Amaravadi, 2011). During the progression of cancer, the activation of PI3KC1/Akt and the loss of the autophagy mediators cause defective autophagy. Defects in both autophagy and apoptosis result in necrotic cell death in metabolically stressed tumor regions, leading to an inflammatory response, DNA damage and consequent tumor progression. Induction of autophagy may contribute to the resistance of cancer cells to chemotherapy. Indeed, cancer chemotherapy combined with an inhibitor of autophagy can improve therapeutic efficacy, proving the pro-survival role of autophagy for cancer cells. Intriguingly, loss of the beclin1 or bif1 gene, which encodes an autophagy mediator, showed hyper-proliferative and increased incidence of lymphoma and other malignancies in mice (Yue et al., 2003; Takahashi et al., 2007). This may be attributable to the function of autophagy in limiting genome damage. Defects in autophagy within the tumor cause genome instability and the accumulation of mutant oncoproteins, facilitating tumor growth (Qu et al., 2003).

Not surprisingly, the autophagic process is necessary for productive viral replication or host cell oncogenic transformation by some oncogenic viruses (Cavignac and Esclatine, 2010; Wen et al., 2010; Dreux and Chisari, 2011). Unlike solid tumors that are constantly under stresses such as hypoxia and nutrient deficiency, which are known to induce autophagy, HTLV-1-induced adult T cell leukemia is a malignancy of peripheral blood. A high level of autophagy occurs spontaneously in HTLV-1-transformed T cells, as seen from our recent data, implying that the virus can take a determining strategy for its own benefit by promoting survival of the infected $\mathrm{T}$ cells. The viral oncoprotein Tax plays a pivotal role in HTLV-1-mediated transformation of T cells by deregulating various oncogenic signaling, including IKK/NF-KB, Jak/Stat and PI3KC1/Akt (Hiscott et al., 1995; Grassmann et al., 2005; Saito et al., 2010). It is conceivable that analyzing the mode of IKK activation may bring critical insights into the mechanism of autophagy induction. The finding that Tax actively recruits IKKs in lipid rafts brings about a new concept in delineating a unique mechanism by which Tax induces persistent activity of $1 \kappa B$ kinases and deregulates autophagy.

Increasing evidence shows that IKB kinases are capable of regulating cellular signaling other than NF-kB cascade (Gantke et al., 2011; Li et al., 2011; Ng et al., 2011; Otani et al., 2011; Luron et al., 2012). It is therefore tempting to investigate whether the lipid raft-associated IKKs are able to execute biological functions in addition to activating NF-KB. By examining HTLV-1-transformed T cells that express Tax, we found that a high level of autophagy is constitutively present while non-Tax expressing ATL cells exhibit an extremely low level of autophagy (Ren et al., unpublished data). Our data show that Tax is able to interact with the autophagy molecule complex containing Beclin1, PI3KC3 and Bif1, and to sequester these autophagy molecules into lipid rafts in IKK $\beta$-dependent manner. Genetic disruption of Beclin1 in HTLV-1-transformed T cells leads to an impaired autophagy along with reduced cell viability. These experimental findings suggest that Tax links the IKK complex to autophagy pathways, thereby promoting survival and proliferation of HTLV-1-transformed T cells (Fig. 2).

\section{FUTURE PERSPECTIVES}

Although genetic and environmental factors may play important roles, the viral components, particularly the viral oncogenic protein Tax, are determining factors in the pathogenesis of HTLV-1-associated leukemia. Tax is central in mediating $\mathrm{T}$ cell oncogenesis at the early stage of malignancy. Tax connects IKB kinase complex to autophagy pathways and executes its functions in activating $1 \mathrm{~KB}$ kinases and in deregulating autophagy in lipid rafts for $\mathrm{T}$ cell survival and proliferation. These experimental findings provide insights into not only the molecular basis of $\mathrm{T}$ cell transformation associated with HTLV-1, but also the development of effective therapies. Directly targeting of Tax, IKB kinase activity, inhibiting autophagy pathways and modulating intracellular cholesterol contents are becoming clear and available options for controlling this aggressive form of leukemia and lymphoma. More studies are needed in order to develop effective and safe therapeutic methods.

\section{DISCLOSURE}

The authors declare no competing financial interests.

\section{FOOTNOTES}

This work was supported by a grant from National Institute of Health to $\mathrm{H}$. Cheng. The content is solely the responsibility of the authors and does not necessarily represent the official views of the National Institutes of Health. 


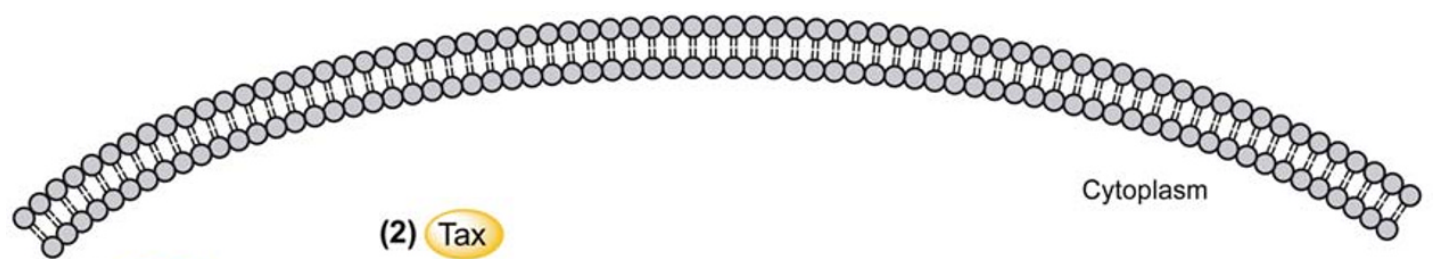

(1) Tax

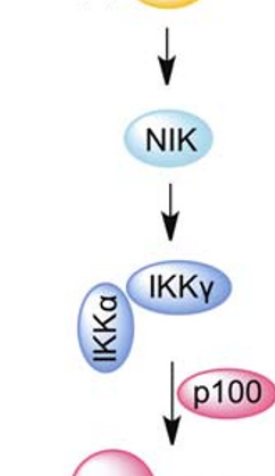

(3) Tax
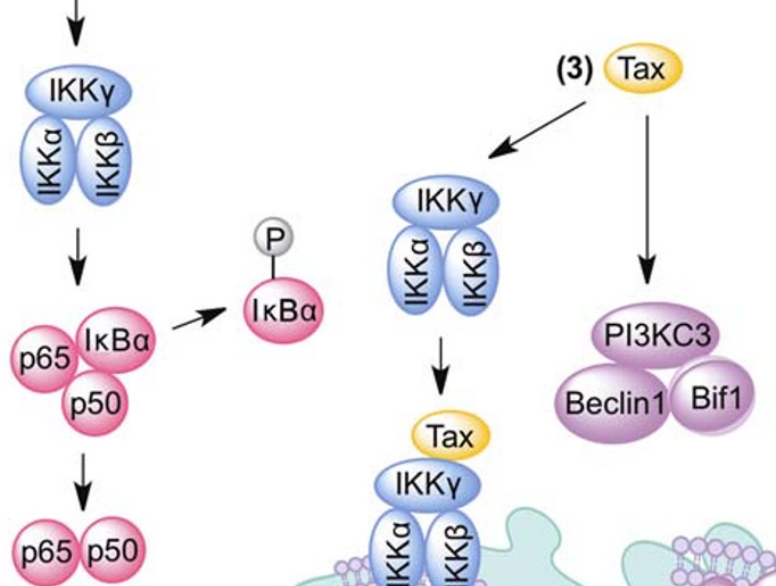

Autophagosome

RelB p52

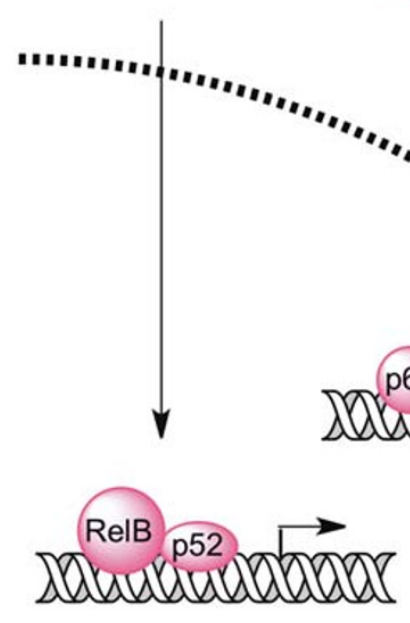

non

non
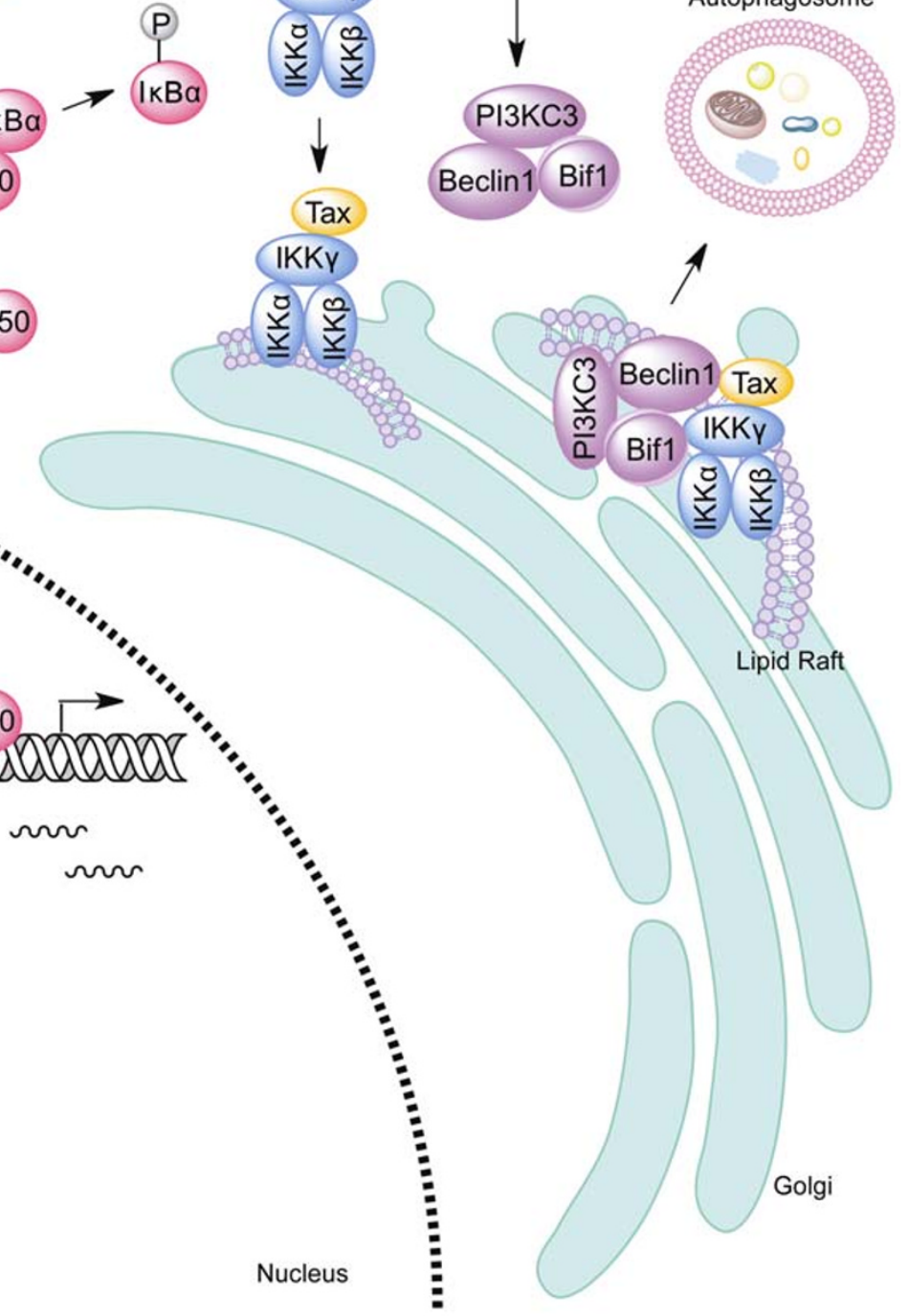

1
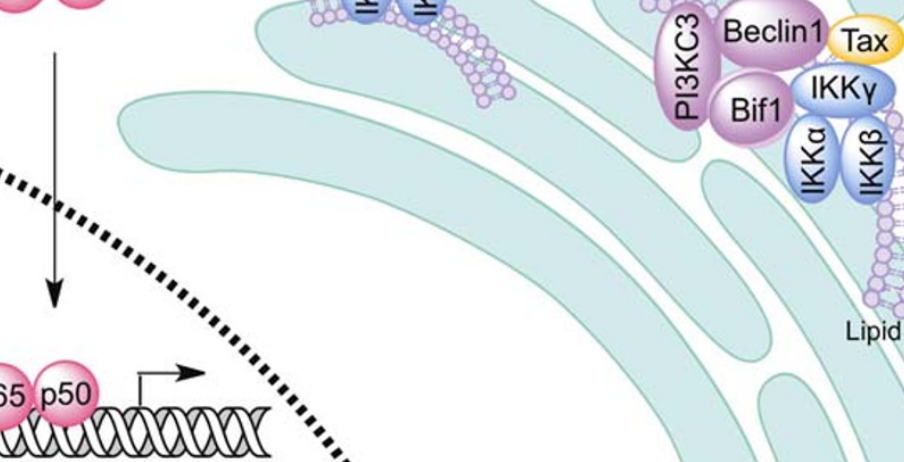


\section{REFERENCES}

Amaravadi, R.K. (2011). Cancer. Autophagy in tumor immunity. Science 334, 1501-1502.

Arcaro, A., Aubert, M., Espinosa del Hierro, M.E., Khanzada, U.K., Angelidou, S., Tetley, T.D., Bittermann, A.G., Frame, M.C., and Seckl, M.J. (2007). Critical role for lipid raft-associated Src kinases in activation of PI3K-Akt signalling. Cell Signal 19, 1081-1092.

Arnold, J., Zimmerman, B., Li, M., Lairmore, M.D., and Green, P.L. (2008). Human T-cell leukemia virus type-1 antisense-encoded gene, Hbz, promotes T-lymphocyte proliferation. Blood 112, 3788-3797.

Bacher, S., and Schmitz, M.L. (2004). The NF-kappaB pathway as a potential target for autoimmune disease therapy. Curr Pharm Des 10, 2827-2837.

Bellon, M., Baydoun, H.H., Yao, Y., and Nicot, C. (2010). HTLV-I Tax-dependent and -independent events associated with immortalization of human primary $\mathrm{T}$ lymphocytes. Blood 115, 2441-2448.

Ben-Neriah, Y., and Karin, M. (2011). Inflammation meets cancer, with NF-kappaB as the matchmaker. Nat Immunol 12, 715-723.

Boehm, J.S., Zhao, J.J., Yao, J., Kim, S.Y., Firestein, R., Dunn, I.F., Sjostrom, S.K., Garraway, L.A., Weremowicz, S., Richardson, A.L., et al. (2007). Integrative genomic approaches identify IKBKE as a breast cancer oncogene. Cell 129, 1065-1079.

Brown, D.A., and London, E. (1998). Functions of lipid rafts in biological membranes. Annu Rev Cell Dev Biol 14, 111-136.

Carter, R.S., Geyer, B.C., Xie, M., Acevedo-Suarez, C.A., and Ballard, D.W. (2001). Persistent activation of NF-kappa B by the tax transforming protein involves chronic phosphorylation of IkappaB kinase subunits IKKbeta and IKKgamma. J Biol Chem 276, 24445-24448.

Cavignac, Y., and Esclatine, A. (2010). Herpesviruses and autophagy: catch me if you can! Viruses 2, 314-333.

Cheng, H., Cenciarelli, C., Nelkin, G., Tsan, R., Fan, D., Cheng-Mayer, C., and Fidler, I.J. (2005). Molecular mechanism of hTid-1, the human homolog of Drosophila tumor suppressor I(2)Tid, in the regulation of NF-kappaB activity and suppression of tumor growth. Mol Cell Biol 25, 44-59.

Cheng, H., Cenciarelli, C., Tao, M., Parks, W.P., and Cheng-Mayer, C. (2002). HTLV-1 Tax-associated hTid-1, a human DnaJ protein, is a repressor of Ikappa B kinase beta subunit. J Biol Chem 277, 20605-20610.

Chu, Z.L., Shin, Y.A., Yang, J.M., DiDonato, J.A., and Ballard, D.W. (1999). IKKgamma mediates the interaction of cellular IkappaB kinases with the tax transforming protein of human $\mathrm{T}$ cell leukemia virus type 1. J Biol Chem 274, 15297-15300.

Criollo, A., Senovilla, L., Authier, H., Maiuri, M.C., Morselli, E., Vitale, I., Kepp, O., Tasdemir, E., Galluzzi, L., Shen, S., et al. (2010). The IKK complex contributes to the induction of autophagy. EMBO J 29, 619-631.

Dreux, M., and Chisari, F.V. (2011). Impact of the autophagy machinery on hepatitis $C$ virus infection. Viruses 3, 1342-1357.

Franchini, G. (1995). Molecular mechanisms of human T-cell leukemia/lymphotropic virus type I infection. Blood 86, 3619-3639.

Furukawa, Y., Kubota, R., Tara, M., Izumo, S., and Osame, M. (2001). Existence of escape mutant in HTLV-I tax during the development of adult T-cell leukemia. Blood 97, 987-993.

Gantke, T., Sriskantharajah, S., and Ley, S.C. (2011). Regulation and function of TPL-2, an IkappaB kinase-regulated MAP kinase kinase kinase. Cell Res 21, 131-145.

Garofalo, T., Lenti, L., Longo, A., Misasi, R., Mattei, V., Pontieri, G.M., Pavan, A., and Sorice, M. (2002). Association of GM3 with Zap-70 induced by $\mathrm{T}$ cell activation in plasma membrane microdomains: GM3 as a marker of microdomains in human lymphocytes. J Biol Chem 277, 11233-11238.

Gaudray, G., Gachon, F., Basbous, J., Biard-Piechaczyk, M., Devaux, C., and Mesnard, J.M. (2002). The complementary strand of the human T-cell leukemia virus type 1 RNA genome encodes a bZIP transcription factor that down-regulates viral transcription. J Virol 76, 12813-12822.

Gerland, L.M., Genestier, L., Peyrol, S., Michallet, M.C., Hayette, S., Urbanowicz, I., Ffrench, P., Magaud, J.P., and Ffrench, M. (2004). Autolysosomes accumulate during in vitro CD8+ T-lymphocyte aging and may participate in induced death sensitization of senescent cells. Exp Gerontol 39, 789-800.

Ghosh, S., May, M.J., and Kopp, E.B. (1998). NF-kappa B and Rel proteins: evolutionarily conserved mediators of immune responses. Annu Rev Immunol 16, 225-260.

Grassmann, R., Aboud, M., and Jeang, K.T. (2005). Molecular mechanisms of cellular transformation by HTLV-1 Tax. Oncogene 24, 5976-5985.

Grassmann, R., Berchtold, S., Radant, I., Alt, M., Fleckenstein, B., Sodroski, J.G., Haseltine, W.A., and Ramstedt, U. (1992). Role of human $\mathrm{T}$-cell leukemia virus type $1 \mathrm{X}$ region proteins in immortalization of primary human lymphocytes in culture. J Virol 66, 4570-4575.

Grossman, W.J., Kimata, J.T., Wong, F.H., Zutter, M., Ley, T.J., and Ratner, L. (1995). Development of leukemia in mice transgenic for the tax gene of human T-cell leukemia virus type I. Proc Natl Acad Sci U S A 92, 1057-1061.

Hansen, G.H., Niels-Christiansen, L.L., Thorsen, E., Immerdal, L., and Danielsen, E.M. (2000). Cholesterol depletion of enterocytes. Effect on the Golgi complex and apical membrane trafficking. J Biol Chem 275, 5136-5142.

Haoudi, A., Daniels, R.C., Wong, E., Kupfer, G., and Semmes, O.J. (2003). Human T-cell leukemia virus-I tax oncoprotein functionally targets a subnuclear complex involved in cellular DNA damage-response. J Biol Chem 278, 37736-37744.

Harhaj, E.W., and Harhaj, N.S. (2005). Mechanisms of persistent NF-kappaB activation by HTLV-I tax. IUBMB Life 57, 83-91.

Harhaj, E.W., and Sun, S.C. (1998). IkappaB kinases serve as a target of CD28 signaling. J Biol Chem 273, 25185-25190.

Harhaj, E.W., and Sun, S.C. (1999). IKKgamma serves as a docking subunit of the IkappaB kinase (IKK) and mediates interaction of IKK with the human T-cell leukemia virus Tax protein. J Biol Chem 274, 22911-22914.

Harhaj, N.S., Sun, S.C., and Harhaj, E.W. (2007). Activation of NF-kappa B by the human T cell leukemia virus type I Tax oncoprotein is associated with ubiquitin-dependent relocalization of I kappa B kinase. J Biol Chem 282, 4185-4192.

Hattori, S., Kiyokawa, T., Imagawa, K., Shimizu, F., Hashimura, E., Seiki, M., and Yoshida, M. (1984). Identification of gag and env gene products of human T-cell leukemia virus (HTLV). Virology 
136, 338-347.

Heino, S., Lusa, S., Somerharju, P., Ehnholm, C., Olkkonen, V.M., and Ikonen, E. (2000). Dissecting the role of the golgi complex and lipid rafts in biosynthetic transport of cholesterol to the cell surface. Proc Natl Acad Sci U S A 97, 8375-8380.

Herbein, G., Varin, A., Larbi, A., Fortin, C., Mahlknecht, U., Fulop, T., and Aggarwal, B.B. (2008). Nef and TNFalpha are coplayers that favor HIV-1 replication in monocytic cells and primary macrophages. Curr HIV Res 6, 117-129.

Hidaka, M., Inoue, J., Yoshida, M., and Seiki, M. (1988). Post-transcriptional regulator (rex) of HTLV-1 initiates expression of viral structural proteins but suppresses expression of regulatory proteins. EMBO J 7, 519-523.

Hiscott, J., Petropoulos, L., and Lacoste, J. (1995). Molecular interactions between HTLV-1 Tax protein and the NF-kappa B/kappa B transcription complex. Virology 214, 3-11.

Huang, J., Ren, T., Guan, H., Jiang, Y., and Cheng, H. (2009). HTLV-1 Tax is a critical lipid raft modulator that hijacks IkappaB kinases to the microdomains for persistent activation of NF-kappaB. J Biol Chem 284, 6208-6217.

Jacobson, S., Shida, H., McFarlin, D.E., Fauci, A.S., and Koenig, S. (1990). Circulating CD8+ cytotoxic T lymphocytes specific for HTLV-I pX in patients with HTLV-I associated neurological disease. Nature 348, 245-248.

Jeang, K.T., Boros, I., Brady, J., Radonovich, M., and Khoury, G. (1988). Characterization of cellular factors that interact with the human T-cell leukemia virus type I p40x-responsive 21-base-pair sequence. J Virol 62, 4499-4509.

Jin, D.Y., Giordano, V., Kibler, K.V., Nakano, H., and Jeang, K.T. (1999). Role of adapter function in oncoprotein-mediated activation of NF-kappaB. Human T-cell leukemia virus type I Tax interacts directly with IkappaB kinase gamma. J Biol Chem 274, 17402-17405.

Kamochi, J., Tokunaga, T., Morino, F., Nagata, J., Tomii, Y., Abe, Y., Hatanaka, H., Kijima, H., Yamazaki, H., Watanabe, N., et al. (2002). Ribozyme mediated suppression of vascular endothelial growth factor gene expression enhances matrix metalloproteinase 1 expression in a human hepatocellular carcinoma cell line. Int $\mathrm{J}$ Oncol 21, 81-84.

Kannagi, M., Harada, S., Maruyama, I., Inoko, H., Igarashi, H., Kuwashima, G., Sato, S., Morita, M., Kidokoro, M., Sugimoto, M., et al. (1991). Predominant recognition of human T cell leukemia virus type I (HTLV-I) pX gene products by human CD8+ cytotoxic T cells directed against HTLV-I-infected cells. Int Immunol 3, 761-767.

Kannagi, M., Matsushita, S., and Harada, S. (1993). Expression of the target antigen for cytotoxic $T$ lymphocytes on adult T-cell-leukemia cells. Int J Cancer 54, 582-588.

Karin, M., and Greten, F.R. (2005). NF-kappaB: linking inflammation and immunity to cancer development and progression. Nat Rev Immunol 5, 749-759.

Koiwa, T., Hamano-Usami, A., Ishida, T., Okayama, A., Yamaguchi, K., Kamihira, S., and Watanabe, T. (2002). 5'-long terminal repeat-selective CpG methylation of latent human T-cell leukemia virus type 1 provirus in vitro and in vivo. J Virol 76, 9389-9397.

Koralnik, I.J., Fullen, J., and Franchini, G. (1993). The p12I, p13II, and p30ll proteins encoded by human T-cell leuke- mia/lymphotropic virus type I open reading frames I and II are localized in three different cellular compartments. J Virol 67, 2360-2366.

Lee, K.Y., D'Acquisto, F., Hayden, M.S., Shim, J.H., and Ghosh, S. (2005). PDK1 nucleates T cell receptor-induced signaling complex for NF-kappaB activation. Science 308, 114-118.

Li, C., Capan, E., Zhao, Y., Zhao, J., Stolz, D., Watkins, S.C., Jin, S., and Lu, B. (2006). Autophagy is induced in CD4+ T cells and important for the growth factor-withdrawal cell death. J Immunol 177, 5163-5168.

Li, L., Ruan, Q., Hilliard, B., Devirgiliis, J., Karin, M., and Chen, Y.H. (2011). Transcriptional regulation of the Th17 immune response by IKK(alpha). J Exp Med 208, 787-796.

Li, Z.W., Chu, W., Hu, Y., Delhase, M., Deerinck, T., Ellisman, M., Johnson, R., and Karin, M. (1999). The IKKbeta subunit of IkappaB kinase (IKK) is essential for nuclear factor kappaB activation and prevention of apoptosis. J Exp Med 189, 1839-1845.

Los, M., Khazaie, K., Schulze-Osthoff, K., Baeuerle, P.A., Schirrmacher, V., and Chlichlia, K. (1998). Human T cell leukemia virus-I (HTLV-I) Tax-mediated apoptosis in activated T cells requires an enhanced intracellular prooxidant state. J Immunol 161, 3050-3055.

Luftig, M., Yasui, T., Soni, V., Kang, M.S., Jacobson, N., Cahir-McFarland, E., Seed, B., and Kieff, E. (2004). Epstein-Barr virus latent infection membrane protein 1 TRAF-binding site induces NIK/IKK alpha-dependent noncanonical NF-kappaB activation. Proc Natl Acad Sci U S A 101, 141-146.

Luron, L., Saliba, D., Blazek, K., Lanfrancotti, A., and Udalova, I.A. (2012). FOXO3 as a new IKK-epsilon-controlled check-point of regulation of IFN-beta expression. Eur J Immunol 42, 1030-1037.

Marriott, S.J., and Semmes, O.J. (2005). Impact of HTLV-I Tax on cell cycle progression and the cellular DNA damage repair response. Oncogene 24, 5986-5995.

Mathew, R., Karantza-Wadsworth, V., and White, E. (2007). Role of autophagy in cancer. Nat Rev Cancer 7, 961-967.

Matsuoka, M., and Green, P.L. (2009). The HBZ gene, a key player in HTLV-1 pathogenesis. Retrovirology 6, 71.

McKinsey, T.A., Brockman, J.A., Scherer, D.C., Al-Murrani, S.W., Green, P.L., and Ballard, D.W. (1996). Inactivation of IkappaBbeta by the tax protein of human T-cell leukemia virus type 1: a potential mechanism for constitutive induction of NF-kappaB. Mol Cell Biol 16, 2083-2090.

Mori, N., Fujii, M., Ikeda, S., Yamada, Y., Tomonaga, M., Ballard, D.W., and Yamamoto, N. (1999). Constitutive activation of NF-kappaB in primary adult T-cell leukemia cells. Blood 93, 2360-2368.

Nerenberg, M., Hinrichs, S.H., Reynolds, R.K., Khoury, G., and Jay, G. (1987). The tat gene of human T-lymphotropic virus type 1 induces mesenchymal tumors in transgenic mice. Science 237 , 1324-1329.

Ng, S.L., Friedman, B.A., Schmid, S., Gertz, J., Myers, R.M., Tenoever, B.R., and Maniatis, T. (2011). IkappaB kinase epsilon (IKK(epsilon)) regulates the balance between type I and type II interferon responses. Proc Natl Acad Sci U S A 108, 21170-21175.

Otani, T., Oshima, K., Onishi, S., Takeda, M., Shinmyozu, K., Yonemura, S., and Hayashi, S. (2011). IKKepsilon regulates cell elongation through recycling endosome shuttling. Dev Cell 20, 
219-232.

Pomerantz, J.L., Denny, E.M., and Baltimore, D. (2002). CARD11 mediates factor-specific activation of NF-kappaB by the T cell receptor complex. EMBO J 21, 5184-5194.

Prasad, S., Ravindran, J., and Aggarwal, B.B. (2010). NF-kappaB and cancer: how intimate is this relationship. Mol Cell Biochem 336, 25-37.

Qu, X., Yu, J., Bhagat, G., Furuya, N., Hibshoosh, H., Troxel, A., Rosen, J., Eskelinen, E.L., Mizushima, N., Ohsumi, Y., et al. (2003). Promotion of tumorigenesis by heterozygous disruption of the beclin 1 autophagy gene. J Clin Invest 112, 1809-1820.

Ratner, L., Portis, T., Robek, M., Harding, J., and Grossman, W. (2000). Studies of the immortalizing activity of HTLV type 1 Tax, using an infectious molecular clone and transgenic mice. AIDS Res Hum Retroviruses 16, 1647-1651.

Rivera-Walsh, I., Waterfield, M., Xiao, G., Fong, A., and Sun, S.C. (2001). NF-kappaB signaling pathway governs TRAIL gene expression and human T-cell leukemia virus-I Tax-induced T-cell death. J Biol Chem 276, 40385-40388.

Rothwarf, D.M., Zandi, E., Natoli, G., and Karin, M. (1998). IKK-gamma is an essential regulatory subunit of the IkappaB kinase complex. Nature 395, 297-300.

Saito, K., Saito, M., Taniura, N., Okuwa, T., and Ohara, Y. (2010). Activation of the PI3K-Akt pathway by human T cell leukemia virus type 1 (HTLV-1) oncoprotein Tax increases Bcl3 expression, which is associated with enhanced growth of HTLV-1-infected T cells. Virology 403, 173-180.

Satou, Y., Yasunaga, J., Yoshida, M., and Matsuoka, M. (2006). HTLV-I basic leucine zipper factor gene mRNA supports proliferation of adult T cell leukemia cells. Proc Natl Acad Sci U S A 103, 720-725

Seiki, M., Hattori, S., Hirayama, Y., and Yoshida, M. (1983). Human adult T-cell leukemia virus: complete nucleotide sequence of the provirus genome integrated in leukemia cell DNA. Proc Natl Acad Sci U S A 80, 3618-3622.

Simons, K., and Ikonen, E. (1997). Functional rafts in cell membranes. Nature 387, 569-572.

Simons, K., and Toomre, D. (2000). Lipid rafts and signal transduction. Nat Rev Mol Cell Biol 1, 31-39.

Sun, S.C., and Ballard, D.W. (1999). Persistent activation of NF-kappaB by the tax transforming protein of HTLV-1: hijacking cellular IkappaB kinases. Oncogene 18, 6948-6958.

Takahashi, Y., Coppola, D., Matsushita, N., Cualing, H.D., Sun, M., Sato, Y., Liang, C., Jung, J.U., Cheng, J.Q., Mule, J.J., et al. (2007). Bif-1 interacts with Beclin 1 through UVRAG and regulates autophagy and tumorigenesis. Nat Cell Biol 9, 1142-1151.

Takeda, S., Maeda, M., Morikawa, S., Taniguchi, Y., Yasunaga, J., Nosaka, K., Tanaka, Y., and Matsuoka, M. (2004). Genetic and epigenetic inactivation of tax gene in adult T-cell leukemia cells. Int J Cancer 109, 559-567.

Usui, T., Yanagihara, K., Tsukasaki, K., Murata, K., Hasegawa, H., Yamada, Y., and Kamihira, S. (2008). Characteristic expression of HTLV-1 basic zipper factor (HBZ) transcripts in HTLV-1 provi- rus-positive cells. Retrovirology 5, 34 .

Van Komen, J.S., Mishra, S., Byrum, J., Chichili, G.R., Yaciuk, J.C., Farris, A.D., and Rodgers, W. (2007). Early and dynamic polarization of T cell membrane rafts and constituents prior to TCR stop signals. J Immunol 179, 6845-6855.

Varmus, H. (1988). Regulation of HIV and HTLV gene expression. Genes Dev 2, 1055-1062.

Wang, D., You, Y., Case, S.M., McAllister-Lucas, L.M., Wang, L., DiStefano, P.S., Nunez, G., Bertin, J., and Lin, X. (2002). A requirement for CARMA1 in TCR-induced NF-kappa B activation. Nat Immunol 3, 830-835.

Wen, H.J., Yang, Z., Zhou, Y., and Wood, C. (2010). Enhancement of autophagy during Iytic replication by the Kaposi's sarcoma-associated herpesvirus replication and transcription activator. J Virol 84, 7448-7458.

$\mathrm{Wu}, \mathrm{X}$., and Sun, S.C. (2007). Retroviral oncoprotein Tax deregulates NF-kappaB by activating Tak1 and mediating the physical association of Tak1-IKK. EMBO Rep 8, 510-515.

$\mathrm{Wu}, \mathrm{X}$., Zhang, M., and Sun, S.C. (2011). Mutual regulation between deubiquitinase CYLD and retroviral oncoprotein Tax. Cell Biosci 1, 27.

Wu, Y.T., Tan, H.L., Huang, Q., Ong, C.N., and Shen, H.M. (2009). Activation of the PI3K-Akt-mTOR signaling pathway promotes necrotic cell death via suppression of autophagy. Autophagy 5 , 824-834.

Xiao, G., Cvijic, M.E., Fong, A., Harhaj, E.W., Uhlik, M.T., Waterfield, M., and Sun, S.C. (2001). Retroviral oncoprotein Tax induces processing of NF-kappaB2/p100 in T cells: evidence for the involvement of IKKalpha. EMBO J 20, 6805-6815.

Xiao, G., and Sun, S.C. (2000). Activation of IKKalpha and IKKbeta through their fusion with HTLV-I tax protein. Oncogene 19, 5198-5203.

Yamaoka, S., Inoue, H., Sakurai, M., Sugiyama, T., Hazama, M., Yamada, T., and Hatanaka, M. (1996). Constitutive activation of NF-kappa B is essential for transformation of rat fibroblasts by the human T-cell leukemia virus type I Tax protein. EMBO J 15, 873-887.

Yin, M.J., Christerson, L.B., Yamamoto, Y., Kwak, Y.T., Xu, S., Mercurio, F., Barbosa, M., Cobb, M.H., and Gaynor, R.B. (1998). HTLV-I Tax protein binds to MEKK1 to stimulate IkappaB kinase activity and NF-kappaB activation. Cell 93, 875-884.

Yip, M.T., and Chen, I.S. (1990). Modes of transformation by the human T-cell leukemia viruses. Mol Biol Med 7, 33-44.

Yoshida, M. (2001). Multiple viral strategies of HTLV-1 for dysregulation of cell growth control. Annu Rev Immunol 19, 475-496.

Yue, Z., Jin, S., Yang, C., Levine, A.J., and Heintz, N. (2003). Beclin 1, an autophagy gene essential for early embryonic development, is a haploinsufficient tumor suppressor. Proc Natl Acad Sci U S A 100, 15077-15082.

Zhao, T., Yasunaga, J., Satou, Y., Nakao, M., Takahashi, M., Fujii, M., and Matsuoka, M. (2009). Human T-cell leukemia virus type 1 bZIP factor selectively suppresses the classical pathway of NF-kappaB. Blood 113, 2755-2764. 